\title{
Co-Firing of Spatially Varying Dielectric Ca-Mg-Silicate and Bi-Ba-Nd-Titanate Composite
}

\author{
Young-Hag Koh, ${ }^{* \dagger}$ Angela Knapp, ${ }^{*}$ and John W. Halloran ${ }^{* *}$ \\ Materials Science and Engineering Department, University of Michigan, Ann Arbor, Michigan 48109 \\ Hae-Won Kim* and Hyoun-Ee Kim* \\ School of Materials Science and Engineering, Seoul National University, Seoul, 151-742, Korea
}

\begin{abstract}
A spatially variant dielectric $\mathrm{Ca}-\mathrm{Mg}-$ silicate $(\mathrm{CMS}) / \mathrm{Bi}-\mathrm{Ba}-$ Nd-titania (BBNT) composite, in which periodic BBNT inclusions were embedded in the CMS matrix, was fabricated using the thermoplastic extrusion. The co-firing behavior of the composite was evaluated in terms of its shrinkage compatibility, thermoplastic compatibility, and chemical compatibility. The noticeable shrinkage mismatch between CMS and BBNT materials was observed. Such shrinkage mismatch strongly affected the interfacial bonding types of the composites. The good interfacial bonding was observed for the composite having BBNT inclusions in the CMS matrix; however, the interfacial cracking and matrix cracking for the opposite design (i.e., CMS inclusions in the BBNT matrix). In addition, the (Ca, Zn)-rich glassy phase in the CMS region migrated into the $B B N T$ region, forming an interfacial reaction layer. The dielectric properties of the CMS, BBNT, and CMS-BBNT mixture were measured to evaluate the spatially variant dielectric CMS/BBNT composite as a novel dielectric substrate.
\end{abstract}

\section{Introduction}

$\mathrm{R}$ ECENTLY, a material optimization procedure was proposed for dielectric composites used as antenna substrates in wireless communication. ${ }^{1-3}$ These new composites are comprised of mosaics of two dielectric materials arranged according to a particular design. These are called "textured dielectrics" in the electromagnetics community. ${ }^{1}$ In this context, the term "textured" does not imply crystallographic texture, but rather an arrangement where the dielectric constant varies with position in the substrate, and are referred to as "spatially variant dielectric composites." In these materials, the dielectric constant varies through the volume of the dielectric substrate. Different dielectric materials are placed in specific locations to create a dielectric contrast, which will modify the resonance properties of the antenna.

These composites have been developed as dielectric substrates for broadband miniature patch antennas. With uniform dielectric substrates, there exists a trade-off relationship between the size reduction and bandwidth. ${ }^{4,5}$ The physical size of the patch antenna can be reduced in reciprocal proportion to the square root of dielectric constant but the miniaturized antenna suffers

P. Davies - contributing editor

Manuscript No. 20259. Received October 31, 2003; approved March 5, 2005 G910.

Supported by the Defense Advanced Research Project under contract No. N00173-01-1-

${ }^{*}$ Member, American Ceramic Society.

${ }^{\star \star}$ Fellow, American Ceramic Society.

† Author to whom correspondence should be addressed. e-mail: kohyh@snu.ac.kr from narrowed bandwidth, low gain, and a degradation in radiation efficiency. However, textured dielectric composites have been found to offer the possibility of constructing antennas with a smaller physical size, without any degradation in the bandwidth or gain performance for a specified frequency range. ${ }^{3}$

These spatially variant textured dielectrics require a mosaic with regions of distinctly different dielectric constant to achieve the desired dielectric contrast. It is preferred to have a single cofired ceramic dielectric. This paper addresses the fabrication of such substrates for designs featuring one dielectric with a permittivity of 10 bonded to another dielectric with a permittivity of 100 . While the actual designs can be complex, ${ }^{3}$ in this paper we address fabrication issues using a simple square grid.

To realize this, the fabrication method must be capable of controlling the local composition and microstructure in two or three dimensions with submillimeter spatial resolution, and the dielectric materials must be able to be co-fired. We adopt thermoplastic extrusion as the fabrication method, since it can produce a 2-dimensional design with controlled geometry and size ${ }^{6,7}$ For the materials, we chose to use low temperature cofired dielectrics (LTCC) since these materials have been formulated in being sintered with similar silver-alloy metallization.

Many kinds of LTCC materials with various dielectric constants have been developed in the form of glass-ceramics. ${ }^{8-15}$ However, when two dielectric oxides are used, the co-firing process constitutes a key step in the manufacture of textured dielectric composites. That is, the different dielectric oxides must have closely matched densification behaviors during sintering (shrinkage compatible) and have very similar thermal expansion behaviors, in order to prevent warping or cracking during cooling (thermoelastic compatibility). Also the reaction between the two dielectric oxides should be minimized (they should be chemically compatible). The situation is more complicated for LTCC materials, because of the presence of the glassy phases, which are liable to migrate from one region to another.

In this article, we address the co-firing behavior of the spatially variant dielectric composite, in which $\mathrm{Bi}-\mathrm{Ba}-\mathrm{Nd}$-titania (BBNT) inclusions were embedded in a $\mathrm{Ca}-\mathrm{Mg}-$ silicate (CMS) matrix, fabricated by thermoplastic extrusion. After the appropriate binder removal, the composite was co-fired at $1000^{\circ} \mathrm{C}$ for $1 \mathrm{~h}$ in air. The co-fired composite was investigated in terms of the shrinkage compatibility, chemical compatibility, and thermoelastic compatibility. The shrinkage and thermoelastic compatibility were evaluated by observing the interfacial bonding type and curvature development, while the chemical compatibility was evaluated by characterizing the interfacial reaction layer. The microstructural evolution, chemical compositions, and crystalline phases of the CMS, BBNT, and interfacial reaction layer were characterized using several analyzing tools. Finally, the dielectric properties of the CMS, BBNT, and CMSBBNT mixture were measured, in order to evaluate the spatially variant dielectric CMS-BBNT composite as a novel dielectric substrate. 


\section{Experimental Procedure}

Commercially available LTCC powders with distinctly different dielectric constants were used: a CMS material with a dielectric constant of 10 (ULF 100, Ferro corp., Cleveland, OH) and a BBNT-based material with a dielectric constant of 100 (ULF 101, Ferro corp.). The thermoplastic compounds were prepared by blending the ceramic powders with molten resins, consisting of ethylene ethyl acrylate (EEA 6182; Union Carbide, Danbury, CT) and isobutyl methacrylate (Paraloid B67; Rohm and Haas, Philadelphia, PA), at $130^{\circ} \mathrm{C}$ using a heated high shear-mixer (PlastiCorder PL 2100 Electronic Torque Rheometer; C. W. Brabender, South Hackensack, NJ). The powders were gradually added to the molten resin and blended at $130^{\circ} \mathrm{C}$, until a solid loading of $52 \mathrm{vol} \%$ was achieved.

Once compounded, each thermoplastic compound was warm-pressed using a $38 \mathrm{~mm}$ square mold at $140^{\circ} \mathrm{C}$ with an applied load of $10 \mathrm{MPa}$ and then extruded through a symmetric 20:1 square reduction die using a piston extruder (Bradford Small Scale Extrusion Unit; Bradford University Research, Ltd., West Yorkshire, U.K.) at $120^{\circ} \mathrm{C}$ at a rate of $3 \mathrm{~mm} / \mathrm{min}$, producing continuous $2 \mathrm{~mm}$ rectangular bars. The extrudate was cut into lengths of $5 \mathrm{~mm}$. These $2 \mathrm{~mm}$ rectangular bars were the building blocks for the composites.

For the model design with inclusions of BBNT in a matrix of CMS, bars of the CMS-thermoplastic compound were arranged around a bar of the BBNT compound, while the opposite was done for the design with inclusions of CMS in a matrix of BBNT. To bond these into a composite rod, the arrangement was warm-pressed again using a $38 \mathrm{~mm}$ square mold at $140^{\circ} \mathrm{C}$ with $10 \mathrm{MPa}$ pressure. The periodic dielectric composites were cut into slices with a thickness of $4 \mathrm{~mm}$ to make "green" composites.

Slow heating was used to remove the thermoplastic binders by heating the composites up to $700^{\circ} \mathrm{C}$ in an alumina tube-furnace in a nitrogen atmosphere, in order to prevent the formation of defects, such as bloating and cracking. Following this, the composite substrates were co-fired in a box-furnace by heating them at $1000^{\circ} \mathrm{C}$ at a rate of $3^{\circ} \mathrm{C} / \mathrm{min}$ for $1 \mathrm{~h}$ in air. The cooling rate was $3^{\circ} \mathrm{C} / \mathrm{min}$, in order to minimize the thermal stress.

To investigate the shrinkage compatibility of the composite, the shrinkage rates of the monolithic CMS and BBNT materials were monitored using a dilatometer (Theta Industries Inc., Port Washington, NY) as a function of temperature up to $1100^{\circ} \mathrm{C}$. After co-firing at various temperatures, the interfacial bonding types and curvature development were observed by optical microscopy and scanning electron microscopy (SEM; The Philips XL30FEG, Philips Electronics N.V., Eindhoven, the Netherlands). The chemical compatibility was evaluated by observing the interfacial reaction layer by SEM, X-ray microanalysis (EPMA; CAMEBAX Electron Microprobe Analyzer, Cameca, Trumbull, CT), and X-ray diffraction (XRD; Rigaku/MSC, TX). Also, the microstructural evolutions and crystalline phases of the CMS and BBNT region were characterized.

The microwave dielectric properties of sintered monolithic CMS and BBNT samples with a diameter of $10 \mathrm{~mm}$ and a height of $5 \mathrm{~mm}$ sintered at various temperatures were measured using a network analyzer (Model HP8720C; Hewlett-Packard, Palo Alto, CA). In order to evaluate the dielectric properties of the interfacial reaction layer, a BBNT-5 $\mathrm{wt} \%$ CMS sample was also tested. The relative dielectric constant $\left(\varepsilon_{\mathrm{r}}\right)$ was measured using the post resonator method, ${ }^{16}$ while the $Q \times f$ value was measured using the transmission cavity method with a copper cavity and Teflon support. ${ }^{17}$

\section{Results and Discussion}

\section{(1) Fabrication of Spatially Variant Dielectric Composite}

A portion of the textured composite substrate in the pre-sintered "green" state appears in Fig. 1. This shows an array of $2 \mathrm{~mm}$ square inclusions of the BBNT material in a matrix of the CMS

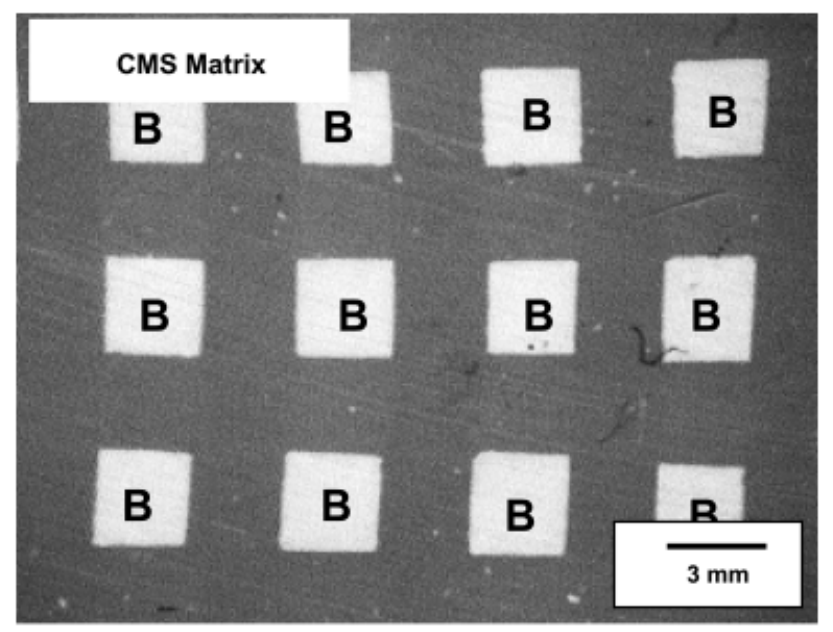

Fig. 1. Optical micrograph of the spatially variant dielectric $\mathrm{Ca}-\mathrm{Mg}$ silicate (CMS)/Bi-Ba-Nd-titania (BBNT) composite, illustrating periodic BBNT inclusions ("B") were embedded in the CMS matrix ("C") before a thermal treatment.

material. The warm pressing step bonded the individual bars of the two compounds by flow of the thermoplastic binder.

\section{(2) Shrinkage Compatibility}

In order to co-fire the two materials, they should have closely matched densification behaviors during sintering and very similar thermal expansion behaviors on cooling. Otherwise, cracks or crack-like defects are likely to occur, as is often the case with ceramic multilayer systems and film-substrate systems. ${ }^{18-21}$ The shrinkage compatibility was evaluated by monitoring the sintering rates of the CMS and BBNT materials as a function of the sintering temperature, as shown in Fig. 2. For both materials, shrinkage started in the early stages with softening of the glassy phase, which enhanced the densification, and then rapidly increased. However, the shrinkage rate of the CMS material (Fig. 2(A)) was faster than that of the BBNT material for all sintering temperatures (Fig. 2(B)). The final linear shrinkages of the CMS and BBNT materials at $1100^{\circ} \mathrm{C}$ were $18.9 \%$ and $17.8 \%$, respectively.

The unconstrained strain mismatch between the CMS and BBNT materials was calculated as a function of the sintering temperature, as shown in Fig. 3. Above $550^{\circ} \mathrm{C}$, the strain mismatch started to build up and reached a maximum of $\sim 4.2 \%$ at a temperature of $850^{\circ} \mathrm{C}$. Thereafter, the strain mismatch

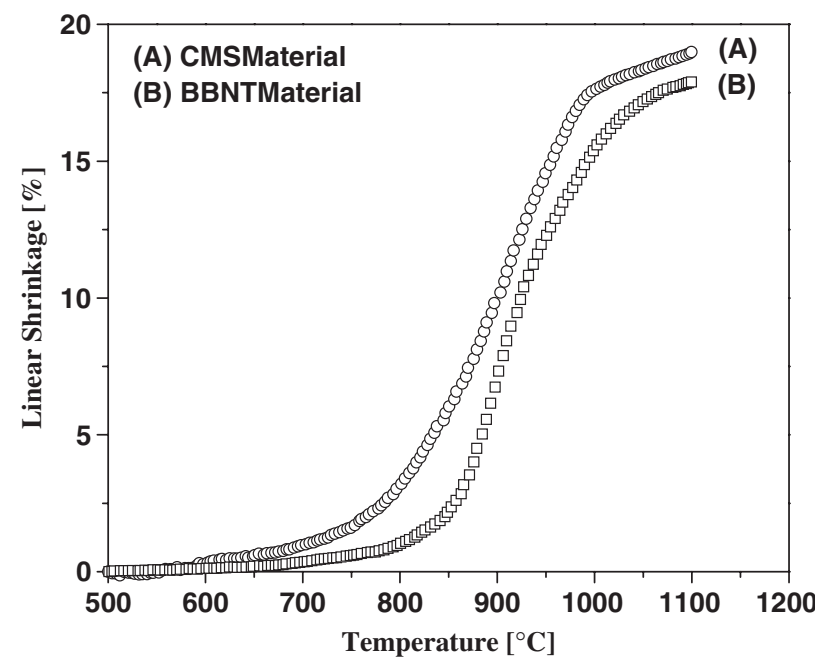

Fig. 2. Linear shrinkages of (A) $\mathrm{Ca}-\mathrm{Mg}-$ silicate (CMS) and (B) $\mathrm{Bi}-\mathrm{Ba}-$ Nd-titania (BBNT) material as a function of sintering temperature, illustrating the faster shrinkage rate of the CMS material. 


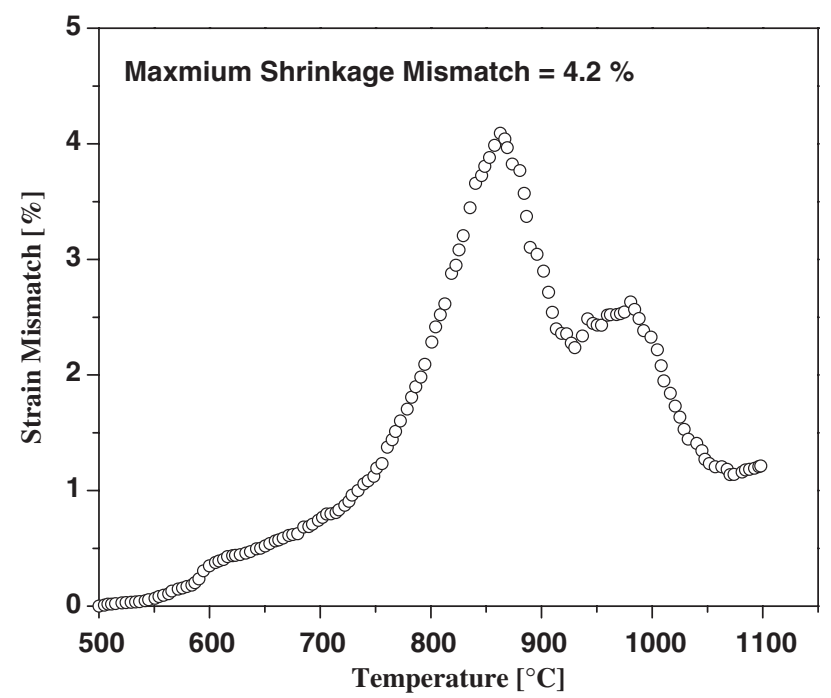

Fig. 3. Strain mismatch between $\mathrm{Ca}-\mathrm{Mg}-$ silicate $(\mathrm{CMS})$ and $\mathrm{Bi}-\mathrm{Ba}-$ Nd-titania (BBNT) material as a function of sintering temperature. *The strain mismatch was calculated from Fig. 2.

decreased, because of the enhanced densification of the BBNT material. Such strain mismatch during co-firing might generate interfacial stress, consequently affecting the interfacial bonding between the CMS and BBNT materials.

There are several possible ways of overcoming interfacial cracking. One is to match the shrinkage rates of the CMS and BBNT materials, by increasing the shrinkage rate of the BBNT or decreasing the shrinkage rate of the CMS, which can be accomplished by modifying the composition. We did not attempt this because we did not want to modify the composition of the LTCC materials. An alternative method is to design a dielectric

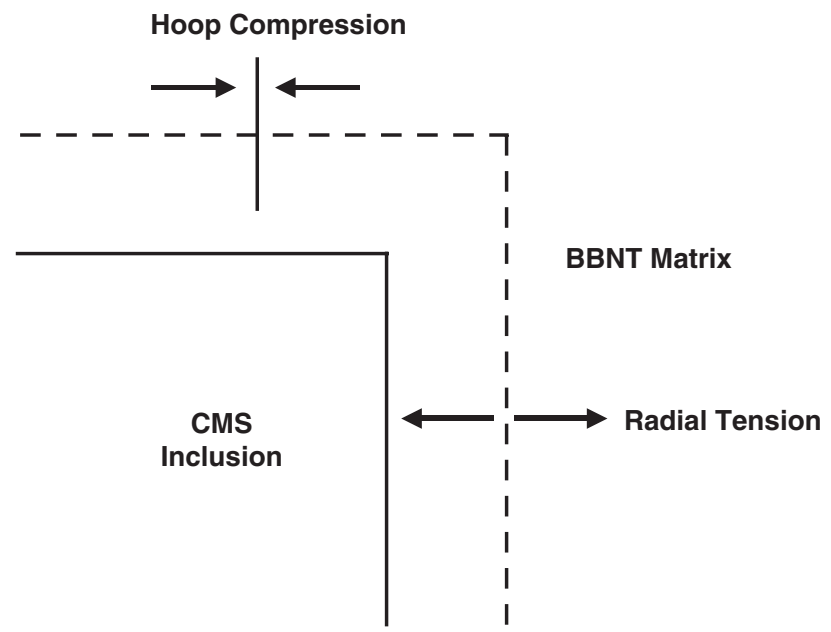

Fig. 5. Schematic of stresses development of the composite having $\mathrm{Ca}-$ $\mathrm{Mg}$-silicate (CMS) inclusions in the $\mathrm{Bi}-\mathrm{Ba}-\mathrm{Nd}-$ titania (BBNT) matrix during co-firing, illustrating radial tension and hoop compression.

composite that can minimize (or change) the interfacial stress generated by strain mismatch during co-firing. ${ }^{22}$ To implement this approach, two types of textures (i.e., BBNT inclusions in the CMS matrix and CMS inclusions in the BBNT matrix) were prepared.

After co-firing, two distinctly different interfacial bonding types were observed, as shown in Figs. 4(A)-(D). In the case of the CMS matrix with BBNT inclusions, the as-fired surface revealed good interfacial bonding between CMS and BBNT materials without generating interfacial cracking or materials cracking (Fig. 4(A)). The inner region of the composite showed good interfacial bonding more clearly (Fig. 4(B)). Even though we did not analyze the coefficients of the thermal expansion of
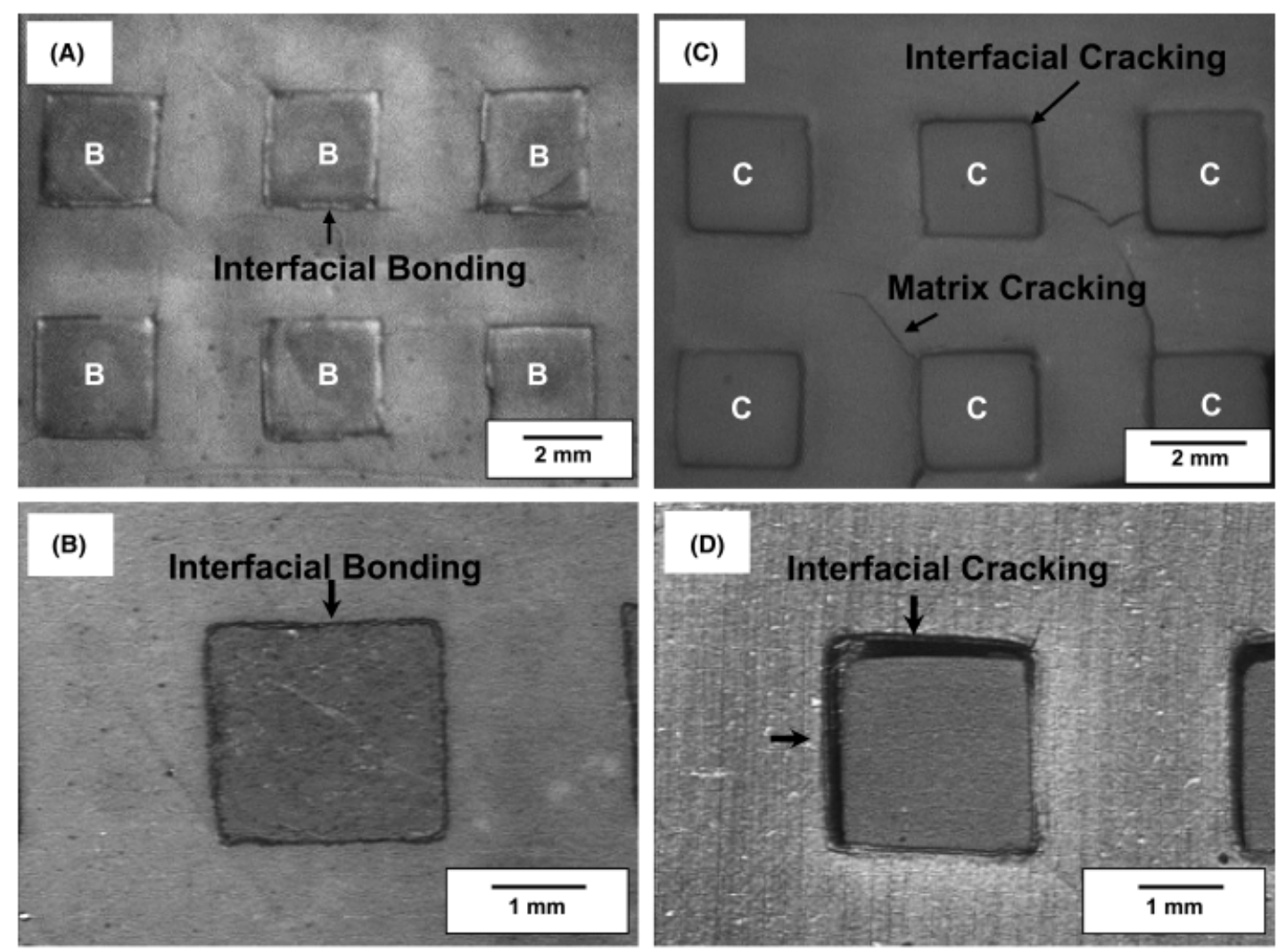

Fig. 4. Optical micrographs of the $\mathrm{Ca}-\mathrm{Mg}$-silicate (CMS)/Bi-Ba-Nd-titania (BBNT) composites co-fired at $1000^{\circ} \mathrm{C}$ for $1 \mathrm{~h}$ in air, illustrating good interfacial bonding for the composite having BBNT inclusions in the CMS matrix (A, B) and interfacial delamination for the composite having CMS inclusions in the BBNT matrix $(\mathrm{C}, \mathrm{D})$. 


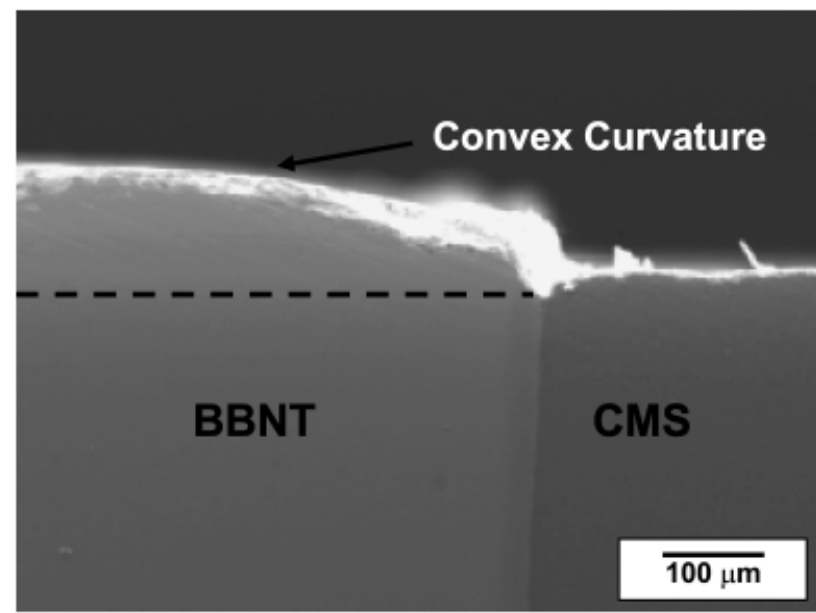

Fig. 6. Scanning electron micrograph of the $\mathrm{Ca}-\mathrm{Mg}$-silicate (CMS)/ $\mathrm{Bi}-\mathrm{Ba}-\mathrm{Nd}-$ titania (BBNT) composite having BBNT inclusions in the CMS matrix after co-firing at $1000^{\circ} \mathrm{C}$ for $1 \mathrm{~h}$ in air, illustrating convex curvature in the BBNT region.

the CMS and BBNT materials quantitatively, it is deemed that thermal stress that arises on cooling is not so high as interfacial cracking or materials cracking occurs. On the other hand, in the case of the BBNT matrix with CMS inclusions, severe interfacial cracking and material cracking were observed, as shown in Fig. 4(C). The inner region showed a large gap between the CMS inclusion and BBNT matrix (Fig. 4(D)), implying that the interfacial cracking took place during sintering rather than on cooling. In other words, once these interfacial cracks are generated during sintering, the CMS inclusion can shrink freely without any stress, leading to the smaller size.

These opposite interfacial bonding types were attributed to the faster shrinkage rate of CMS compared with that of BBNT during co-firing. Considering that the CMS material shrinks more than the BBNT material during sintering from a matched zero-strain condition, the presence of isolated CMS inclusion in the BBNT matrix would result in hydrostatic tension in the CMS region and radial tension and hoop compression in the BBNT region, as shown in Fig. 5. On the other hand, isolated BBNT inclusion in the CMS matrix would result in hydrostatic compression in the BBNT region, and radial compression and hoop tension in the CMS region (not shown). If the CMS material is significantly tougher than the BBNT material, one might expect hoop cracks to occur in the BBNT material or interfacial cracking in the case of the BBNT matrix with CMS inclusions (see Fig. 4(C)), while BBNT buckling on the surface would be expected in the case of the CMS matrix with BBNT inclusions (Fig. 4(A)).

In addition, strain mismatch that arises during co-firing developed the convex curvature of the BBNT inclusion because of the compression of the BBNT region caused by its being surrounded by the CMS regions, as shown in Fig. 6. Such convex or concave curvatures have been frequently observed because of the constrained sintering, when multi-material is co-fired. ${ }^{23-25}$ If the CMS inclusion has good interfacial bonding with the BBNT matrix during shrinkage, the CMS inclusion would be expected to have a concave curvature; however, no concave curvature was observed, implying the interfacial cracking took place during sintering rather than on cooling.

\section{(3) Microstructure and Interfacial Reaction}

The typical microstructural evolutions of the CMS/BBNT composite after co-firing at $1000^{\circ} \mathrm{C}$ for $1 \mathrm{~h}$ in air are shown in Figs. 7(A)-(D). At low magnification, three distinct regions are visible, namely the CMS region, the interfacial reaction layer, and the BBNT region (Fig. 7(A)). The CMS region showed fine grains of diopside phase $\left(\mathrm{CaMgSi}_{2} \mathrm{O}_{6}\right)$, identified by XRD and EPMA analyses, as shown in Fig. 7(B). Other phases, such as Zn-substituted akermanite $\left(\mathrm{Ca}_{2}\left(\mathrm{Mg}_{1-x} \mathrm{Zn}_{x}\right) \mathrm{Si}_{2} \mathrm{O}_{7}\right)$ and a $\mathrm{ZrO}_{2}$
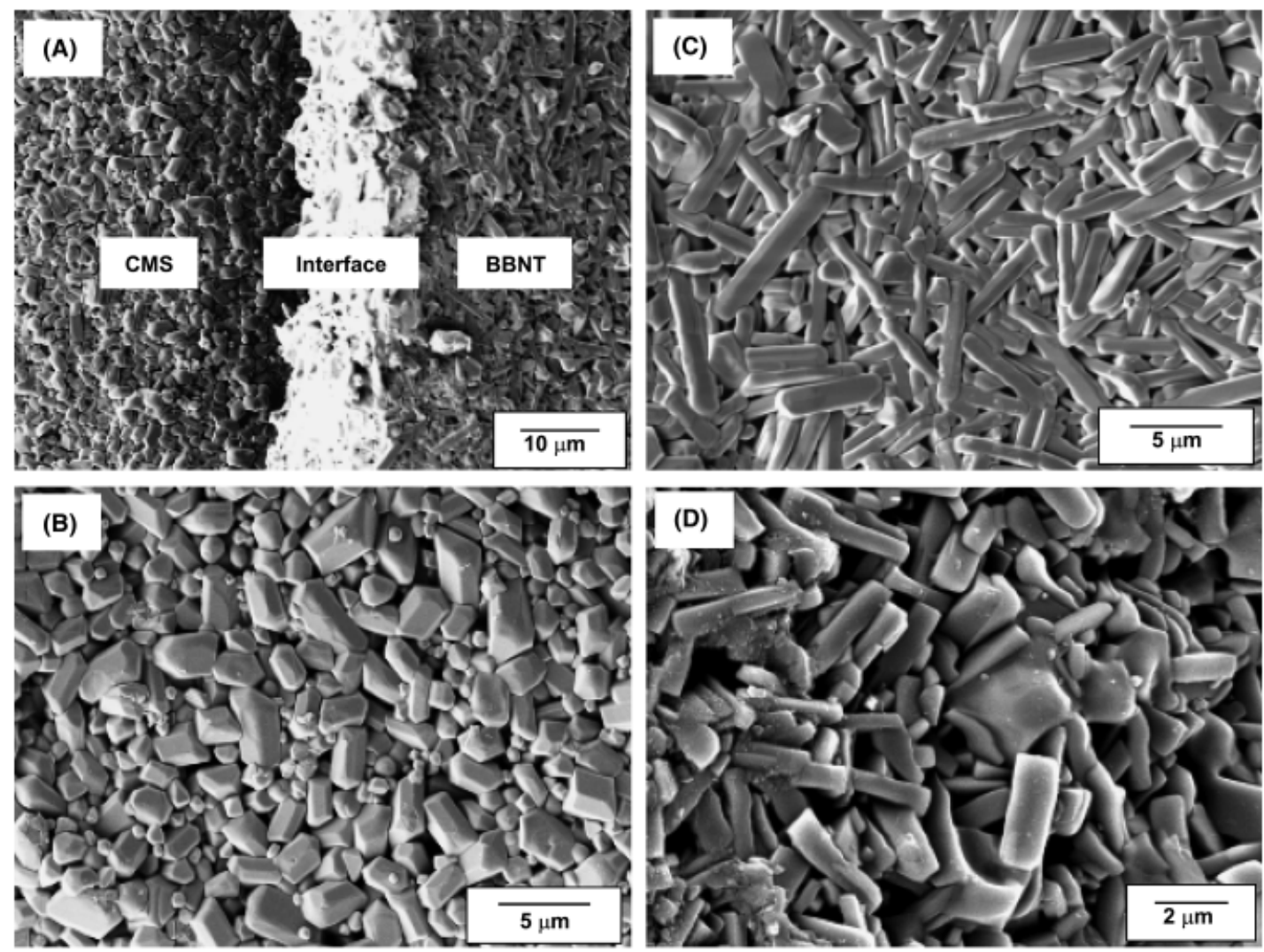

Fig. 7. Scanning electron micrographs of the $\mathrm{Ca}-\mathrm{Mg}$-silicate $(\mathrm{CMS}) / \mathrm{Bi}-\mathrm{Ba}-\mathrm{Nd}-$ titania $(\mathrm{BBNT})$ composite after co-firing at $1000^{\circ} \mathrm{C}$ for $1 \mathrm{~h}$ in air, illustrating (A) three regions at low magnification, (B) CMS region, (C) BBNT region, and (D) interface region. 


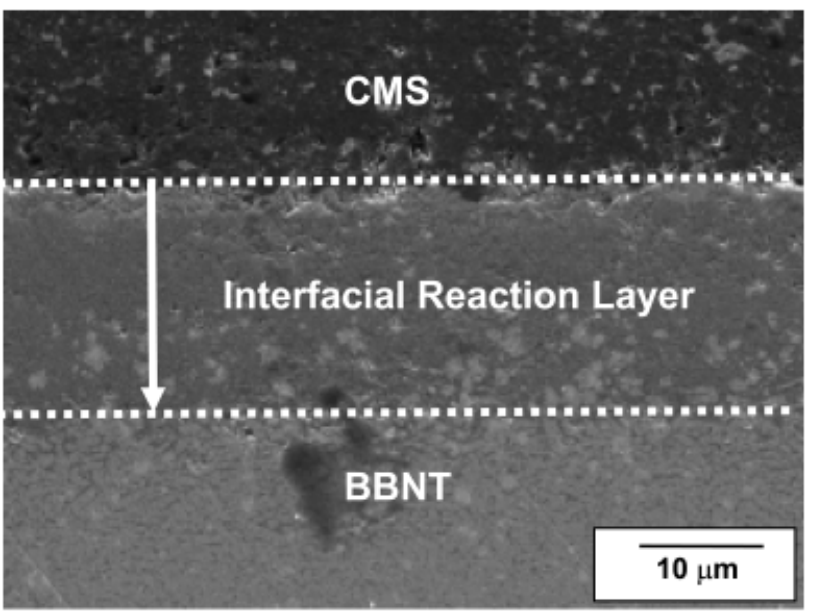

Fig. 8. Scanning electron micrograph of the $\mathrm{Ca}-\mathrm{Mg}$-silicate (CMS)/ $\mathrm{Bi}-\mathrm{Ba}-\mathrm{Nd}-$-titania (BBNT) composite after co-firing at $1000^{\circ} \mathrm{C}$ for $1 \mathrm{~h}$ in air, illustrating the interfacial reaction layer.

phase, were also detected. On the other hand, the BBNT region showed columnar grains of $\mathrm{Bi}$-substituted $\mathrm{Ba}-\mathrm{Nd}$-titanate that had a $\mathrm{Ba}_{6-3 x} \mathrm{Nd}_{8+2 x} \mathrm{Ti}_{18} \mathrm{O}_{54}$ crystalline structure, as shown in Fig. 7(C). In addition, Sn-substituted Bi-Nd-titanate was observed as a secondary phase. Since the interfacial reaction layer was formed in the region with convex curvature, it is believed that this region belonged to the original BBNT region. The grain morphologies on the interface showed similar to that of the BBNT region but less elongated grains were observed, as shown in Fig. 7(D).

In order to characterize the interfacial reaction layer, the CMS/BBNT composite was ground and polished. A typical SEM micrograph showed the $\sim 10 \mu \mathrm{m}$ thick interfacial reaction layer that was formed because of the migration of the glassy phase from the CMS to the BBNT region (Fig. 8). We previously observed that the $(\mathrm{Ca}, \mathrm{Zn})$-rich glassy phase favorably migrated to the surface during sintering of the monolithic CMS material. ${ }^{26}$ In addition, pores were observed in the CMS region near the interface, presumably because of the lack of the glassy phase.

The migration of a glassy phase from the CMS and BBNT regions was confirmed by energy dispersive spectroscopy (EDS) analysis, as shown in Fig. 9. As the distance from the interface to

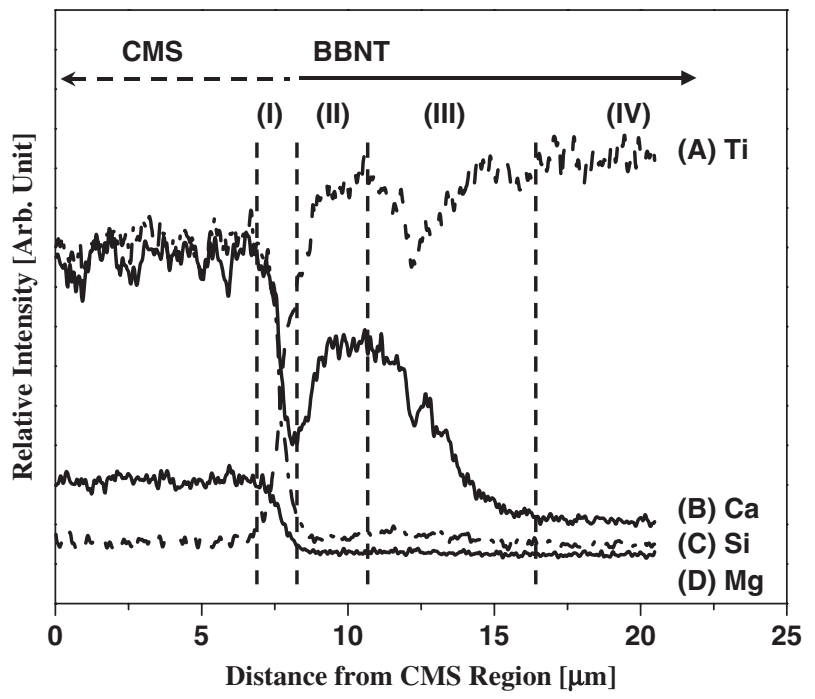

Fig.9. Energy dispersive spectroscopy analyses of (A) $\mathrm{Ti}$, (B) $\mathrm{Ca},(\mathrm{C})$ $\mathrm{Si}$, and (D) $\mathrm{Mg}$ element as a function of distance from the $\mathrm{Ca}-\mathrm{Mg}-$ silicate (CMS) to the $\mathrm{Bi}-\mathrm{Ba}-\mathrm{Nd}$-titania (BBNT) region, after co-firing at $1000^{\circ} \mathrm{C}$ for $1 \mathrm{~h}$ in air.

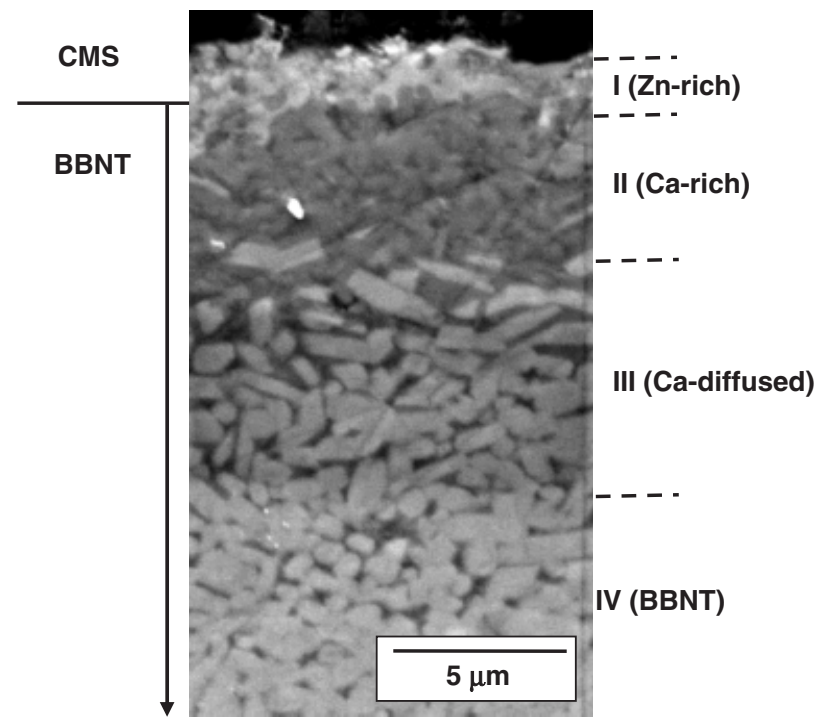

Fig. 10. Scanning electron micrograph illustrating the interfacial reaction region after co-firing at $1000^{\circ} \mathrm{C}$ for $1 \mathrm{~h}$.

BBNT region increased, the concentration of elemental $\mathrm{Ti}$ increased and remained constant (Fig. 9(A)). The other elements in the BBNT material showed similar trends, implying that there was no migration of any ion from the BBNT region to the CMS region. On the other hand, as the distance from the interface to the BBNT region increased, the concentration of elemental $\mathrm{Ca}$ gradually decreased (Fig. 9(B)), while the concentrations of elemental Si and Mg (Figs. 9(C) and (D)) decreased dramatically and then disappeared. It should be noticed that a sharp decline in the concentration of $\mathrm{Ca}$ element was observed near the interface, where the presence of elemental $\mathrm{Zn}$ was detected by EPMA analysis. These observations imply that the (Ca, $\mathrm{Zn}$ )-rich glassy phase in the CMS region migrates to the interface, and $\mathrm{Ca}^{2+}$ ions further migrates into the BBNT region, while $\mathrm{Zn}^{2+}$ ions become segregated at the CMS region near the interface.

Such migration of the glassy phase from the CMS to BBNT region affected the microstructural evolutions of the interfacial reaction layer, as shown in Fig. 10. Four distinctive layers were observed, which is in good agreement with the EDS analyses (regions I-IV). In the CMS region near the interface (region I), the presence of elemental $\mathrm{Zn}$ and a relatively small amount of elemental $\mathrm{Ca}$ was detected in the EPMA analysis. That is, $\mathrm{Zn}^{2+}$ ions became segregated at the CMS region near the interface (Zn-rich CMS region) and $\mathrm{Ca}^{2+}$ ions further migrated into the $\mathrm{BBNT}$ region. Beneath this region (region II), an area of dark contrast was observed, indicating the presence of a Ca-rich glassy phase (Ca-rich BBNT region). In region III, the bright region (i.e., columnar grains) was found to consist of $\mathrm{Ca}$-substituted BBNT (Ca-diffused BBNT). Region IV exhibited the typical microstructure of BBNT material, indicating negligible migration of the Ca-rich glassy phase (BBNT region).

\section{(4) Dielectric Properties}

Since it was not possible to determine the dielectric properties of the CMS/BBNT composite directly, we determined the dielectric properties of the monolithic CMS and BBNT materials processed by the thermoplastic method. The relative dielectric properties, such as the dielectric constants and $Q \times f$ values, of the CMS and BBNT materials sintered at $1000^{\circ} \mathrm{C}$ for $1 \mathrm{~h}$ in air, are shown in Fig. 11. Both materials showed similar values to those of the sample prepared by dry-pressing or tape casting, indicating that the materials are not degraded by the thermoplastic processing. Briefly, the CMS material had a low dielectric constant of 9 and a high $Q \times f$ value above 15000 at $10 \mathrm{GHz}$, while the BBNT material had the dielectric constant of 97 and $Q \times f$ of 1175 at $4.8 \mathrm{GHz}$. In addition, we measured the dielectric prop- 


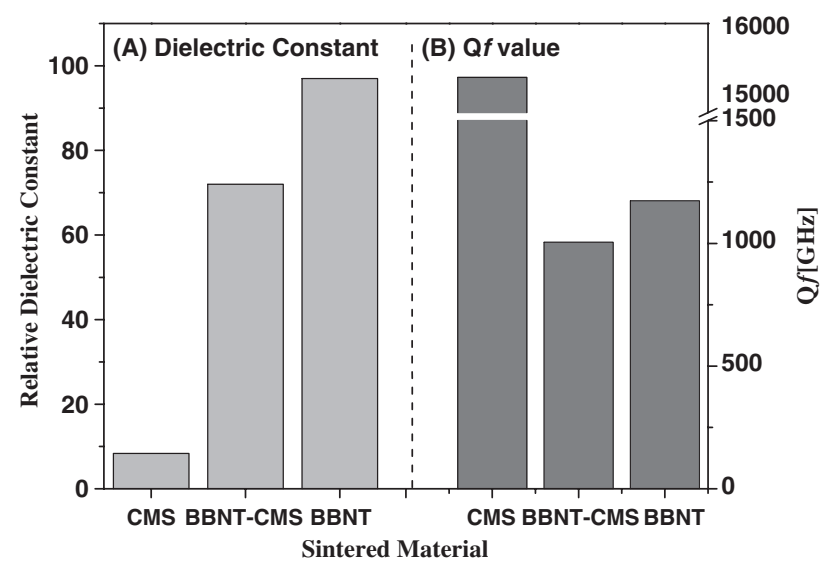

Fig. 11. Dielectric properties of $\mathrm{Ca}-\mathrm{Mg}-$-silicate (CMS), $\mathrm{Bi}-\mathrm{Ba}-\mathrm{Nd}-$ titania (BBNT) $-5 \mathrm{wt} \% \mathrm{CMS}$, and $\mathrm{BBNT}$ material sintered at $1000^{\circ} \mathrm{C}$ for $1 \mathrm{~h}$ in air. ${ }^{*}$ The dielectric properties were measured at 10, 4.8, and 4.6 GHz for CMS, BBNT, BBNT-CMS, respectively.

erties of the BBNT sample containing $5 \mathrm{wt} \% \mathrm{CMS}$ to evaluate the properties of the interfacial reaction layer. A dielectric constant of 71 and a $Q \times f$ value of $1105 \mathrm{GHz}$ at $4.6 \mathrm{GHz}$ were obtained for this material, as shown in Fig. 11. The relatively modest degradation of the $Q \times f$ suggests that the reaction products are not excessively lossy. These results suggest that one might obtain suitable dielectric properties of the CMS/BBNT composite that will be used as a dielectric substrate in patch antennas.

\section{Summary and Conclusion}

The thermoplastic extrusion was used to fabricate a spatially variant dielectric $\mathrm{CMS} / \mathrm{BBNT}$ composite as a novel dielectric substrate, in which periodic BBNT inclusions were embedded in the CMS matrix. After appropriate binder removal, the composite was co-fired at $1000^{\circ} \mathrm{C}$ for $1 \mathrm{~h}$ in air. The co-firing behavior was evaluated in terms of its shrinkage compatibility, thermoplastic compatibility, and chemical compatibility. The shrinkage mismatch between CMS and BBNT materials played a key role in determining the interfacial bonding type of the composite. In other words, the composite having BBNT inclusions in the CMS matrix showed the good interfacial bonding, while the composite having CMS inclusions in the BBNT matrix showed the interfacial cracking and matrix cracking because of the faster shrinkage of the CMS material. In addition, the (Ca, $\mathrm{Zn}$ )-rich glassy phase in the CMS region migrated into the BBNT region, forming the approximately $10 \mu \mathrm{m}$ thick interfacial reaction layer. The reasonable dielectric properties of the monolithic CMS, BBNT, CMS-BBNT mixture were obtained. These results imply that the spatially variant dielectric CMS/ BBNT composite can be fabricated by thermoplastic extrusion in an effective way and co-fired with tailored properties.

\section{References}

${ }^{1}$ G. Kiziltas, C. Yilmaz, J. L. Volakis, N. Kikuchi, and J. W. Halloran, "Design of Metamaterial Textures for Microwave Applications"; pp. 388-91 in 2002 IEEE Symposium on Antennas and Propagation, Vol. II, San Antonio, TX, 2002.

${ }^{2}$ G. Kiziltas, J. L. Volakis, and N. Kikuchi, "Metamaterial Design Via the Density Method"; pp. 748-51 in 2002 IEEE Symposium on Antennas and Propagation, Vol. I, San Antonio, TX, 2002.

${ }^{3}$ G. Kiziltas, D. Psychoudakis, J. L. Volakis, and N. Kikuchi, “Topology Optimization of Dielectric Substrates for Bandwidth Improvements of Patch Antennas," IEEE Trans. Antennas Propag., 51 [10] 2732-43 (2003).

${ }^{4}$ I. S. Ghosh, A. Hilgers, T. Schlenker, and R. Porath, "Ceramic Microwave Antennas for Mobile Applications,” J. Eur. Ceram. Soc., 21 [15] 2621-8 (2001).

${ }^{5}$ G. P. Gauthier, A. Courtay, and G. M. Rebeiz, "Microstrip Antennas on Synthesized Low Dielectric-Constant Substrates," IEEE Trans. Antennas Propag., 45 [8] 1310-4 (1997).

${ }^{6}$ C. H. Hoy, A. Barda, M. Griffith, and J. W. Halloran, "Microfabrication of Ceramics by Co-Extrusion," J. Am. Ceram. Soc., 81 [1] 152-8 (1998).

${ }^{7}$ Y. H. Koh, H. W. Kim, H. E. Kim, and J. W. Halloran, "Fabrication and Compressive Strength of Macrochannelled Tetragonal Zirconia Polycrystals with Calcium Phosphate Coating Layer," J. Mater. Res., 18 [9] 2009-12 (2003).

${ }^{8}$ A. H. Kumar, P. W. McMillan, and R. R. Tummala, "Glass-Ceramic Structures and Sintered Multilayered Substrates Thereof with Circuit Patterns of Gold, Silver, or Copper"; U.S. Patent No. 4301 324, 1981.

${ }^{9}$ R. R. Tummala, "Ceramic and Glass-Ceramic Packaging in the 1990s," J. Am. Ceram. Soc., 74 [5] 895-908 (1991).

${ }^{10}$ Ferro Corp., Technical publication of FERRO TAPE-A6. Ferro Corp., Santa Barbara, CA, 1996.

${ }^{11}$ Ferro Corp., Technical publication of FERRO CHIP COMPONET MATERILAS. Ferro Corp., Santa Barbara, CA, 1999.

${ }^{12}$ S. H. Knickerbocker, A. H. Kumar, and L. W. Herron, "Cordierite GlassCeramics for Ceramic Packaging," Am. Ceram. Soc. Bull., 72 [1] 90-5 (1993).

${ }^{13}$ S. X. Dai, R. F. Huang, and D. L. Wilcox Sr., "Use of Titanates to Achieve a Temperature-Stable Low-Temperature Cofired Ceramic Dielectric for Wireless Applications," J. Am. Ceram. Soc., 85 [4] 828-32 (2002).

${ }^{14}$ O. Dernovsek, A. Naeini, G. Preu, W. Wersing, M. Eberstein, and W.A Schiller, "LTCC Glass-Ceramic Composites for Microwave Applications," J. Eur. Ceram. Soc., 21 [10-11] 1693-7 (2001).

${ }^{15}$ D. M. Mattox, S. R. Gurkovich, J. A. Olenick, and K. M. Mason, "Low Dielectric Constant Alumina-Compatible, Co-Fired Multilayer Substrate," Ceram. Eng. Sci. Proc., 9 [11-12] 1567-78 (1988).

${ }^{16}$ B. W. Hakki and P. D. Coleman, "A Dielectric Resonator Method of Measuring Inductive Capacities in the Millimeter Range," IRE Trans. Microwave Theory Technol., 8, 402-10 (1960).

${ }^{17}$ D. Kaifez and P. Guillion, Dielectric Resonators, pp. 327-76. Artech House, Norwood, MA, 1986.

${ }^{18}$ P. Z. Cai, D. J. Green, and G. L. Messing, "Constrained Densification of $\mathrm{Al}_{2} \mathrm{O}_{3} / \mathrm{ZrO}_{2}$ Hybrid Laminates: I. Experimental Observations of Processing Defects," J. Am. Ceram. Soc., 80 [8] 1929-39 (1997).

${ }^{19}$ S. Ho, C. Hillman, F. F. Lange, and Z. Suo, "Surface Cracking in Layers under Biaxial, Residual Compressive Stress," J. Am. Ceram. Soc., 78 [9] 2353-9 (1995).

${ }^{20} \mathrm{~T}$. Cheng and R. Raj, "Flaw Generation During Constrained Sintering of Metal-Ceramic and Metal-Glass Multilayer Films," J. Am. Ceram. Soc., 72 [9] 1649-55 (1989).

${ }^{21}$ R. Bordia and A. Jagota, "Crack Growth and Damage in Constrained Sintering Films," J. Am. Ceram. Soc., 76 [10] 2475-85 (1993).

${ }^{22}$ P. S. Fisher, C. O. Jordan, and P. N. Shepherd, "Low Temperature Co-Fired Ceramic with Improved Shrinking Control"; U.S. Patent No. 6711 029, 2004.

${ }^{23}$ J. H. Jean and C. R. Chany, "Camber Development During Cofiring AgBased Low Dielectric Constant Ceramic Package," J. Mater. Res., 12 [10] 2743-50 (1997).

${ }^{24}$ J. H. Jean and C. R. Chang, "Effect of Densification Mismatch on Camber Development During Cofiring of Nickel-Based Multilayer Ceramics Capacitors," J. Am. Ceram. Soc., 80 [9] 2401-6 (1997).

${ }^{25}$ R. Zuo, L. Li, Z. Gui, X. Hu, and C. Ji, "Effects of Additives on the Interfacial Microstructure of Cofired Electrode-Ceramic Multilayer Systems," J. Am. Ceram. Soc., 85 [4] 787-93 (2002).

${ }^{26}$ Y. H. Koh, A. Knapp, J. W. Halloran, H. W. Kim, and H. E. Kim, "Microstructural Evolution and its Effect on Dielectric Properties of $\mathrm{Ca}-\mathrm{Mg}-$ Silicate Glass Ceramics," J. Mater. Res. (submitted). 